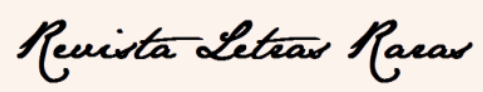

ISSN: $2317-2347$ - v. 7, n. 2 (2018)

\title{
Alice lobo / Wolf-Alice ${ }^{1}$
}

Angela Carter*

Se esta menina maltrapilha, com os lóbulos das orelhas malhados, pudesse falar como nós ela diria que é um lobo, mas ela não sabe falar, embora uive quando está só mas, uivar não é a palavra adequada, pois ela é jovem o suficiente para fazer o barulho que os filhotes fazem, borbulhante, delicioso, como uma panela com banha quando vai ao fogo. Às vezes, os ouvidos aguçados de seus parentes adotivos podem ouvi-la através do abismo irreparável da ausência; eles respondem da longínqua floresta de pinheiros e do pico da montanha. Os sons que entoam cruzam o céu noturno; eles estão tentando falar com ela, mas eles não conseguem porque ela não entende a linguagem deles, mesmo sabendo como usá-la, pois, ela não é um lobo, apesar de ter sido amamentada por um.

Sua língua ofegante está pendurada; seus lábios vermelhos são grossos e frescos. Suas pernas são longas, finas e musculosas. Seus cotovelos, mãos e joelhos são calejados, já que ela corre sobre as quatro patas. Ela nunca anda; ela trota ou galopa. Seu ritmo não é o nosso.

Duas patas observa; quatro patas fareja. Seu longo nariz sempre se meche, farejando todos os cheiros que encontra. Com essa ferramenta, ela investiga minuciosamente tudo que vislumbra. Ela consegue captar mais coisas do mundo do que

\footnotetext{
${ }^{1}$ O livro de Angela Carter (1940-1992) que contém o conto aqui traduzido está divulgado em acesso livre e gratuito em <https://uniteyouthdublin.files.wordpress.com/2016/01/1-the-bloody-chamber-and-otherstories-1979.pdf>.

*Autora: Angela Carter, conhecida por abordar temas pouco convencionais (como pornografia, fetiche sexual, estupro, incesto, canibalismo entre outros), nasceu em 1940 na cidade de Eastbourne, no sul da Inglaterra, onde foi registrada sob o nome de Angela Olive Stalker. Publicou nove romances, quatro coletâneas de contos, um livro de ensaios, duas coletâneas sobre jornalismo, um volume de peças para rádio etc. Carter ainda recebeu os prêmios John Llewellyn Rhys, em 1967; Somerset Maugham, em 1979; James Tait Black Memorial, em1985. Fonte de inspiração para muitas escritoras, Angela Carter faleceu em 16 de fevereiro de 1992, em Londres.

Traduzido por:

Walter Vieira Barros, graduado em Letras-Inglês pela Universidade Federal de Campina Grande (UFCG), mestrando do Programa de Pós-Graduação em Linguagem e Ensino da UFCG, waltervieirabarros@gmail.com

Sinara de Oliveira Branco, Doutora em Letras/Tradução (UFSC) e professora da Universidade Federal de Campina Grande (UFCG). Membro do Programa de Pós-Graduação em Linguagem e Ensino da UFCG, sinarabranco@gmail.com
} 


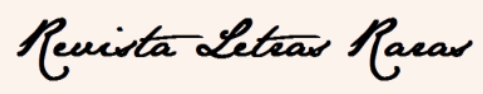

ISSN: $2317-2347$ - v. 7, n. 2 (2018)

nós, através das suas narinas precisas, peludas e sensitivas, de maneira que a sua visão restrita não a incomoda. Seu nariz é mais afiado à noite do que os nossos olhos durante o dia, então é a noite que ela prefere, quando a luz da lua não machuca seus olhos e extrai todo o tipo de fragrância da floresta onde ela pode vagar. Mas os lobos se mantêm afastados das espingardas dos camponeses, e ela não vai mais encontrá-los lá.

Ombros largos, braços longos e ela dorme enrolada como uma bola, com se tentasse agarrar a sua cauda. Nada nela é humano, exceto o fato de que ela não é um lobo; é como se o pelo que ela pensa que tem, tivesse derretido para dentro de sua pele e se tornado parte dela, mesmo que ele não exista. Assim como as criaturas selvagens, ela vive sem futuro. Ela vive apenas o tempo presente, uma fuga do contínuo, um mundo de imediatismo sensual, sem esperança e sem desespero.

Quando ela foi encontrada na cova do lobo ao lado do cadáver crivado de balas da sua mãe adotiva, ela não passava de um pequeno fragmento marrom que rosnava por trás de seus cabelos castanhos e eles, a princípio, pensaram que ela era um filhote e não uma criança; ela se virou para os seus salvadores com seus caninos afiados até que eles a amarraram a força.

Ela passou seus primeiros dias entre nós, agachada e completamente imóvel, encarando a parede branca da sua cela no convento para onde foi levada. As freiras jogavam água nela, cutucavam-na com varas para despertá-la. Ela tomava o pão das mãos das freiras e corria para um canto e devorava-o de costas para elas; foi um grande dia para as noviças quando ela aprendeu a sentar sobre as pernas e a pedir comida. As freiras perceberam que se ela fosse tratada com delicadeza, ela não seria intratável. Ela aprendeu a reconhecer seu próprio prato; depois, a beber no copo. As freiras perceberam que ela poderia facilmente aprender alguns truques, mas ela não sentia frio, então levou um tempo para convencê-la a passar uma roupa sobre sua cabeça para cobrir sua nudez. Ainda assim ela parecia selvagem, impaciente e caprichosa no temperamento; quando a madre superiora tentou ensiná-la a dar graças por ter sido retirada da alcateia, ela arqueou as costas, bateu no chão, se recolheu para o canto mais afastado da capela, rastejou, tremeu, urinou, defecou - parecia ter retrocedido, inteiramente, ao estado natural. Assim, sem o menor escrúpulo, esses nove dias de espanto e de constrangimento contínuo da criança foram entregues à família desolada e não santificada do Duque. 


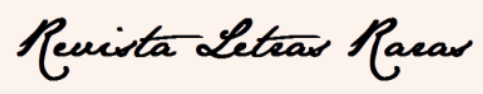

ISSN: $2317-2347$ - v. 7, n. 2 (2018)

Deixada no castelo, ela bufou e farejou e cheirou e sentiu o odor de carne, mas não o cheiro de enxofre, nem de familiaridade. Ela se agachou sobre os tornozelos e suspirou igual a um cachorro, apenas expulsando o ar, sem alívio ou resignação.

O Duque era ressequido como papel velho; sua pele seca era áspera contra os lençóis de cama, à medida que os jogava para esticar suas pernas finas marcadas por antigas cicatrizes de espinhos. Ele vive completamente só numa mansão sombria, e agora com uma criança, que tem pouco em comum conosco, assim como ele. Seu quarto é pintado com terracota, oxidado por uma lavagem de dor, parecendo um açougue ibérico, mas nada pode abalá-lo desde que ele parou de se olhar no espelho.

Ele dorme numa cama talhada de chifres de ferro forjados em preto fosco até que a lua, a governanta das transformações e superintendente dos sonâmbulos, bata na janela com seu dedo indicador e atinja seu rosto: então os olhos dele se abrem. À noite, aqueles olhos grandes, inconsoláveis e vorazes são substituídos por suas pupilas dilatadas e reluzentes. Seus olhos enxergam apenas o apetite. Aqueles olhos se abrem para devorar o mundo, onde ele não vê seu próprio reflexo em lugar algum; ele atravessou o espelho e de agora em diante, vive do outro lado das coisas.

A luz da lua derrama-se como leite sob o gramado congelado; em noites de luar como essas, de clima metamórfico, as pessoas dizem que se você for insensato o bastante para se aventurar tarde da noite, pode facilmente encontrá-lo, rondando os terrenos da igreja com metade de um torso suculento pendurando em suas costas. A luz branca percorre o terreno de novo e de novo até que todo o espaço fique claro e ele saia deixando pegadas enquanto corre e uiva ao redor dos túmulos fazendo sua festa lupina.

No nascer das primeiras horas do solstício de inverno, todas as portas são fechadas por quilômetros. As vacas se mexem irritadas no curral quando ele passa, os cachorros choramingam e escondem seus focinhos entre as patas. Ele carrega sobre seus ombros frágeis o fardo do medo; ele é visto como o devorador de cadáveres, o ladrão de corpos que invade a privacidade dos mortos. Ele é branco como um leproso, com longas unhas e nada o detém. Não adianta encher o cadáver com alho, ele apenas vai se deleitar com o tratamento: cadáver à la provençale. Ele vai usar o crucifixo para se coçar e se debruçar sobre a fonte e beber sedentamente a água benta.

Ela dorme nas cinzas quentes e macias da lareira; camas são armadilhas, ela não deitaria em uma. Ela consegue fazer algumas poucas tarefas que as freiras a ensinaram, 


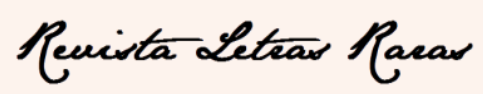

ISSN: 2317-2347 - v. 7, n. 2 (2018)

ela varre os cabelos, as vértebras e as falanges que sujam o quarto do Duque, ela arruma a cama dele quando ele sai ao pôr do sol e as feras cinzas uivam como se soubessem que essa transformação é uma imitação. Grosseiros com suas presas, entre eles são delicados, se o Duque fosse um lobo, eles o expulsariam da matilha, ele teria que andar por quilômetros atrás deles de forma desengonçada, rastejando em submissão até a matança; depois que todos tivessem comido e ido dormir, para roer os ossos e mastigar a pele. No entanto, como ela foi amamentada por lobos nas montanhas, onde sua mãe deu à luz e a deixou, sua ajudante, que não é nem lobo nem mulher, não sabe de nada além de fazer as tarefas para ele.

Ela cresceu com as feras selvagens. Se você pudesse levá-la, com seus trapos imundos e transtorno selvagem, para o Éden, onde Eva e Adão viviam agachados em um campo de margaridas, catando os piolhos um do outro, talvez, ela fosse a criança inteligente, que lidera todos, e seu silêncio e seus uivos seriam tão autênticos quanto qualquer outra linguagem da natureza. Em um mundo de feras e flores, ela seria o broto de carne na gentil boca do leão: mas como uma maçã mordida consegue cicatrizar-se?

Mutilação é seu destino; de vez em quando, ela emitirá um ruído involuntário, como se as cordas vocais não usadas em sua garganta fossem uma harpa eólica, que se move com os impulsos aleatórios do ar, os seus sussurros, mais obscuros do que os sons de um mudo.

Profanações familiares no cemitério do vilarejo. O caixão foi aberto com o desleixo com que uma criança abre os presentes na manhã de Natal, seu conteúdo não foi encontrado, a não ser um pedaço de pano do véu de noiva que enrolava o cadáver esvoaçando no portão dos terrenos da igreja, apontando o caminho que ele tinha seguido, em direção ao seu sombrio castelo.

Em um curto espaço de tempo, no transe de pertencer àquele exílio, a menina cresceu ao redor de coisas que não sabia nomear nem compreender. Como pensava, como se sentia, esta estranha perene com seus pensamentos peludos e de sentidos primitivos, que vivia em um fluxo de impressões mutáveis; não há palavras que descrevam o modo como ela negociava o abismo entre seus sonhos, aqueles despertares tão estranhos quanto seu sono. Os lobos a acolheram porque sabiam que ela era um lobo imperfeito; nós a isolamos por medo das suas imperfeições, porque as imperfeições nos 


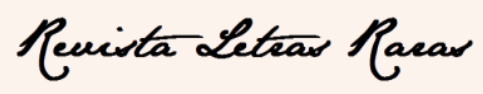

ISSN: $2317-2347$ - v. 7, n. 2 (2018)

mostravam quem nós poderíamos ter sido. Assim o tempo passou, e ela mal percebeu. Então veio o sangramento.

Sua primeira menstruação a deixou desnorteada. Ela não sabia o que aquilo significava e as primeiras suposições que lhe ocorreram foram voltadas para as possíveis causas. A lua estava brilhando na cozinha quando ela acordou e sentiu o gotejar entre suas pernas e para ela pareceu que um lobo, que talvez estivesse interessado nela, como os lobos são, e que morava na lua? teria mordiscado a sua vagina enquanto ela dormia, submetendo-a a uma série de mordidas afetuosas e gentis que não a fizeram acordar, mas afiadas o bastante para romper sua pele. $\mathrm{O}$ formato dessa teoria estava desfocado, mas mesmo assim, pode-se retirar um pedaço de razão, como se tivesse caído de uma semente lançada em seu cérebro pelo pé de um pássaro voador.

O fluxo continuou por alguns dias, o que lhe pareceu algo sem fim. Ela ainda não tinha noção de passado, ou de futuro, ou de duração, apenas de momentos imediatos e sem dimensões. À noite, ela rondava a casa vazia em busca de trapos para estancar o sangramento; ela tinha aprendido algumas noções básicas de higiene no convento, o suficiente para saber como enterrar os seus excrementos e limpar-se dos seus fluidos naturais, no entanto, as freiras não tinham os meios para informá-la como deveria agir, não foi a estranheza do fato, mas sim a vergonha que a levou a agir daquela forma.

Ela encontrou toalhas, lençóis e fronhas no guarda-roupa, que não era aberto desde que o Duque veio ao mundo com todos os dentes em sua boca para morder o mamilo de sua mãe e chorar. Ela encontrou um vestido de festa, que fora usado apenas uma vez, em armários cobertos por teia de aranha e amontoados em um canto daquele quarto sangrento, roupas sociais e de enterros que embrulhavam os itens do cardápio do Duque. Ela rasgou pedaços dos tecidos mais absorventes e desajeitadamente fez uma fralda. No percurso daquela perambulação, ela esbarrou no espelho cuja superfície o Duque passou como um vento gélido.

Primeiramente, ela tentou cheirar o próprio reflexo; então, após cheirá-lo diligentemente, ela logo percebeu que ele não tinha cheiro. Ela machucou o focinho no vidro gelado e quebrou as suas patas tentando lutar com aquela estranha. Ela olhou, irritada, e depois admirada, com o fato de que a estranha imitava todos os seus gestos, quando ela levantava a pata dianteira para se coçar, ou quando arrastava o traseiro pelo tapete empoeirado para se livrar de um pequeno desconforto nos quadris. Ela esfregou a 


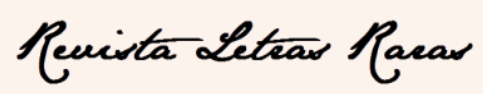

ISSN: 2317-2347 - v. 7, n. 2 (2018)

cabeça no seu reflexo para se mostrar amigável, e sentiu uma superfície gelada, sólida e imóvel entre ela e o reflexo - talvez algum tipo de jaula invisível? Apesar dessa barreira, ela se sentia sozinha o bastante para chamar a criatura para brincar com ela, mostrando todos os dentes de uma forma sorridente; imediatamente recebeu o mesmo convite. Ela se alegrou; começou a girar em volta de si mesma, latindo animadamente, mas quando ela se afastou um pouco do espelho, ela parou no meio do seu êxtase, confusa, ao ver que sua nova amiga diminuía no tamanho.

A luz da lua se derramou dentro do quarto do Duque por de trás de uma nuvem, e ela viu o quanto aquele lobo não lobo, que brincava com ela, era pálido. A lua e os espelhos têm algo em comum: você não pode ver o que está por trás deles. Sob o luar, Alice Lobo olhou para si mesma no espelho e se perguntou se o que via era a fera que tinha vindo mordê-la à noite. Prontamente, sua audição aguda captou passos no corredor; trotando de volta para a cozinha, ela encontrou o Duque com a perna de um homem sobre o ombro. As unhas dos pés arranhando as escadas enquanto ela passeava sem curiosidade, numa serenidade absolutamente inviolável, inocência verminosa.

Rapidamente o fluxo parou. Ela o esqueceu. A lua desapareceu; mas aos poucos reapareceu. Quando a lua visitou mais uma vez a cozinha com toda intensidade, Alice Lobo foi surpreendida novamente pelo sangramento, com uma pontualidade que transformou sua vaga noção de tempo. Ela aprendeu a esperar por esses sangramentos, a utilizar os trapos quando eles viessem, e, por fim, a enterrá-los ordenadamente. O ciclo se regularizou e ela entendeu o princípio do relógio perfeitamente, mesmo se todos os relógios fossem retirados do covil, onde ela e o Duque habitavam em solidões separadas, sendo possível dizer que ela descobriu a ação do tempo através do ciclo contínuo.

Quando ela se enrolou entre as cinzas, a cor, a textura e o calor trouxeram do passado a sensação da barriga da sua mãe adotiva; sua primeira lembrança consciente, tão dolorida quanto a primeira vez que as freiras pentearam o seu cabelo. Ela uivou um pouco, em uma trajetória firme e profunda, para obter um consolo inescrutável na resposta dos lobos, uma vez que o mundo ao seu redor estava tomando forma. Ela percebeu uma diferença essencial entre ela e as coisas ao seu redor que se pode afirmar que ela não poderia desvendar - as árvores e a grama dos prados não se assemelhavam mais à emanação do seu nariz questionador nem ao levantar de suas orelhas, ainda 


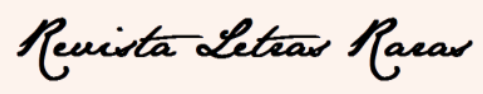

ISSN: $2317-2347$ - v. 7, n. 2 (2018)

assim autossuficiente, uma espécie de pano de fundo para ela, que esperava a sua chegada para lhe dar significado. Ela se viu além deles e seus olhos, com uma clareza sombria, assumiu um olhar velado, introspectivo.

Ela passava horas examinando a pele nova que achava que tinha nascido por causa do sangramento. Ela lambia os pelos com a língua e alisava o cabelo com as unhas. Ela examinava seus novos seios com curiosidade e, eles a fizeram lembrar dos cogumelos que ela encontrava, às vezes, em seus passeios noturnos pela floresta, uma desconcertante aparição natural; mas para sua surpresa, ela encontrou uma pequena trilha de pelos novos entre suas pernas. Ela mostrou os pelos para sua amiga do espelho, que a confortou mostrando os dela.

O amaldiçoado Duque assombra o cemitério; ele acredita que seja ao mesmo tempo mais e menos do que um homem, como se essa diferença obscena fosse um sinal divino. Durante o dia, ele dorme. Seu espelho reflete fielmente sua cama, mas nunca a forma escassa dentro das cobertas bagunçadas.

Em certas noites claras de luar, quando ficava sozinha em casa, ela pegava os vestidos de festas da avó do Duque e rolava no veludo suave e rendas abrasivas, pois fazer isso deliciava sua pele adolescente. Sua amiga do espelho girava as roupas velhas ao redor de si, franzindo o nariz em delírio nos aromas antigos, mas ainda recentes de almíscar e civeta, que despertava das mangas e dos corpetes. Essa habitual enfadonha fidelidade aos seus movimentos a despertou para a lamentável possibilidade de que sua companheira não passava de uma ingênua variedade de sombras lançada sobre grama ensolarada. Não teria ela e o resto da ninhada brincado com suas sombras há um tempo? Ela cutucou com o nariz ágil a parte de trás do espelho; encontrando apenas poeira, uma aranha enganchada na teia, um amontoado de trapos. Uma pequena umidade escorreu dos cantos dos seus olhos, e agora sua relação com o espelho era mais íntima, uma vez que descobriu que era ela dentro do espelho.

Ela apalpou e balançou por um momento o vestido que o Duque guardava atrás do espelho. A poeira foi imediatamente sacudida; ela, experimentalmente, inseriu as patas dianteiras nas mangas. Apesar de o vestido estar rasgado e amassado, ele era tão branco e com uma textura tão sinuosa que ela decidiu, antes de vesti-lo, se lavar para retirar todas as cinzas de seu corpo, com a água do poço do quintal que, com toda a sua 


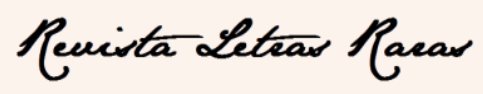

ISSN: $2317-2347$ - v. 7, n. 2 (2018)

astúcia, aprendeu a manusear a bomba. No espelho, ela viu o quanto o vestido branco a fazia brilhar.

Mesmo não conseguindo correr sobre duas pernas por causa das anáguas, ela trotava em seu vestido novo para investigar os odores das sebes de Outubro, como uma debutante do castelo, impressionada consigo mesma, mas, ao mesmo tempo, ainda cantando um triunfo melancólico para os lobos, pois agora ela sabia como se vestir e isso demonstrava um sinal visível de diferença entre ela e os lobos.

Suas pegadas na terra úmida são bonitas e ameaçadoras, como aquelas deixadas pelo Homem da Sexta-Feira.

O jovem marido da noiva que morreu passou um longo tempo planejando a sua vingança. Ele encheu a igreja com um arsenal de sinos, livros e velas; um batalhão de balas de prata; eles trouxeram em um vagão da cidade dez galões de água benta, que foi abençoada pelo próprio Arcebispo, para afogar o Duque, se as balas saltassem para fora dele. Eles se reuniram na igreja para entoar uma litania e esperar por aquele responsável pelas primeiras mortes do inverno.

Ela passou a sair à noite com mais frequência; a paisagem se une à sua frente, ela a informa de sua presença. Ela dá significado à paisagem.

Ela achou que a congregação da igreja parecia estar tentando imitar, sem sucesso, o coro dos lobos. Ela emprestou-lhes a sua própria voz como assistência, uma voz educada por um tempo, se balançando sobre seus calcanhares perto do portão do terreno da igreja; então, suas narinas se mexeram para capturar o mau cheiro de morte, que disse a ela que seu amigo do castelo estava próximo; levantando a cabeça, o que seus novos olhos de espiã viram senão o lorde do castelo, que era cheio de teia de aranha, na tentativa de exercer seus rituais canibais?

E se suas narinas se incendiarem desconfiadas com o mau cheiro sufocante de incenso e as dele não, é porque ela é mais sensível do que ele. Ela irá, então, correr, correr! quando escutar o barulho de balas, porque foram elas que mataram a sua mãe adotiva; logo, como os mesmos galopes rápidos e apressados, encharcado de água benta, ele também correrá, até que o jovem viúvo dispare a bala de prata que roçará o ombro do Duque e arrancará metade da sua pele fictícia, de modo que ele se levantará como um bípede qualquer, mancando de forma angustiante da melhor maneira que puder. 


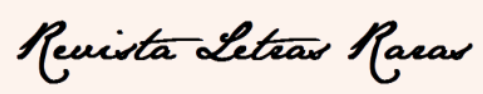

ISSN: $2317-2347$ - v. 7, n. 2 (2018)

Quando eles viram a noiva saltar para fora das lápides e correr em direção ao castelo com o lobisomem aos tropeços atrás dela, os camponeses acharam que a vítima mais amada do Duque teria voltado para cuidar do assunto com as suas próprias mãos. Eles saíram correndo e gritando da presença fantasmagórica vingativa.

Pobre Duque ferido... preso entre dois estados estranhos, uma transformação interrompida, um mistério incompleto, agora ele está estendido e se contorcendo em sua cama no quarto que parece uma tumba micênica, uivando como um lobo com o pé preso em uma armadilha ou como uma mulher em trabalho de parto e sangra.

A princípio, ela estava com medo quando escutou os gemidos de dor, achando que ela a machucaria novamente. Ela rondou a cama, rosnando e cheirando a ferida dele, que não tinha o mesmo cheiro que tinha a ferida dela. Então, ela foi condolente como sua mãe, cinza e magra; ela pulou na cama do Duque e lambeu, sem hesitação, sem nojo, com uma seriedade delicada e rápida, o sangue e a sujeira de suas bochechas e testa.

A lucidez do luar iluminou o espelho pendurado na parede vermelha; o vidro racional, o mestre do visível, registrou imparcialmente a menina cantarolando.

Ao continuar com os cuidados, esse vidro, com uma lentidão infinita, se rendeu à força reflexiva do seu próprio material de construção. Aos poucos, foi aparecendo dentro do espelho, como a imagem em papel fotográfico, que, primeiro, emerge como um tracejado sem forma, a presa capturada em sua própria rede, então se firma ainda mais forte e sombreada no esboço, até que finalmente se torna tão vívida quanto a própria vida, como se trouxesse finalmente à tona, por meio de sua língua macia, úmida e suave, o rosto do Duque.

\section{REFERÊNCIAS}

CARTER, Angela. Wolf-Alice. In: The bloody chamber and other stories.

London: Penguin, 1993. p. 81-86.

Recebimento: 22/07/2018

Aceite: $14 / 09 / 2018$ 